\title{
The Curatorial Turn and Opera: On the Singing Deaths of Maria Callas. A Conversation with Marina Abramović and Marko Nikodijević*
}

\author{
Jelena Novak
}

Marina Abramović is a conceptual and performance artist with a particular interest in the relationship between the artist and the audience. She is especially interested in exploring the extreme limits of her (the artist's) body. In recent years, she has nurtured these interests by restaging some of her earlier works of performance art. To chart some of the more important stages of her career I single out a few key works. In Rhythm o (1974) Abramović stood silent and motionless for six hours in a gallery in Naples, while members of the audience were allowed to do to her whatever they wanted, having at their disposal seventy-two objects. The Great Wall Walk (1988) was performed with her then partner Ulay; they walked for ninety days from opposite ends of the Great Wall of China, and when they finally met, they ended their relationship and said goodbye to each other. Balkan Baroque (1997) reflected on the horrors and tragedies unfolding in post-Yugoslavia. In The Artist is Present (2010) Marina sat motionless in a chair at the MOMA (New York) for ninety days, eight to ten hours per day, gazing into the eyes of members of the audience who took turns sitting in front of her one by one. In 2011 Abramović collaborated with Robert Wilson on

* The conversation transcribed here took place via Zoom on October 15, 2020, as the first talk in the Resvés Ópera Series of Conversations organized by CESEM, FCSH, Universidade NOVA de Lisboa. For more information about this initiative see: https://cesem.fcsh.unl.pt/ resves-opera/.

The talk was moderated by Jelena Novak. Some questions were taken from the members of the audience and that is further indicated in the footnotes. The author would like to thank Katarina Kostić for her help with transcribing the interview. The article was made with the support of CESEM - Research Center for Sociology and Aesthetics of Music, NOVA Lisbon University, FCSH, UID/EAT/o0693/2019, with the financial support of FCT through National funds, under the Norma Transitória - DL 57/2016/CP1453/CToo54. 
the music theater piece The Life and Death of Marina Abramović. Although some people already considered that piece an opera, 7 Deaths of Maria Callas (2020) is actually Abramovićs first opera project.

In 7 Deaths of Maria Callas Abramović used operatic music by five historical composers of the Western canon: Giuseppe Verdi, Giacomo Puccini, Vincenzo Bellini, Gaetano Donizetti, and Georges Bizet. One living composer, Marko Nikodijević, was invited to assemble all these separate strands into a single fabric. Nikodijević wrote the Introduction, then a kind of epilogue "The Eighth Death," and also some interludes conceived as "cloud musics," as he calls them, which were incorporated between the arias.

Like Marina Abramović, Nikodijević was born in Yugoslavia, where he completed his composition studies at the Belgrade Faculty of Music. He then moved to Germany, where he built a successful international career. Nikodijević has been influenced by techno music and by developments in advanced technology, including fractal procedures and computer music. His music is often freighted with a kind of melancholy that is somehow filtered through carefully calculated structural procedures. ${ }^{1}$ Nikodijević has himself composed an opera: VIVIER. Ein Nachtprotokoll (2013-14), a chamber opera in 6 scenes dealing with the Canadian queer icon of new music Claude Vivier. The opera is related to Vivier's life, but also to his unusual death.

The basic form of 7 Deaths of Maria Callas is simple. Seven arias were selected from the mainstream operatic repertoire, arias that have been performed by soprano Maria Callas in an unforgettable manner. Seven sopranos were engaged, each taking one of the leading roles from the following operas: La Traviata, Otello (Verdi), Tosca, Madama Butterfly (Puccini), Carmen (Bizet), Lucia di Lammermoor (Donizetti), Norma (Bellini). The arias are separated by electronic interludes (Nikodijević, with sound design by Luka Kozlovački). While the singer is performing an aria on stage, a short silent film (directed by Nabil Elderkin) is projected on stage as a kind of music video. In those videos Abramović and the actor Willem Dafoe comment on operatic deaths in surreal, fantastical, and sometimes absurd scenes. Unexpectedly, the arias are heard as a film music sequence.

1 For further details about Marko Nikodijevićs music, see Jelena Novak, "Music as an Aggregate of Colours: A Conversation with Marko Nikodijević," New Sound International Journal of Music 57, n. 1 (2021): 1-17, http://ojs.newsound.org.rs/index.php/NS/article/view/77/117. 


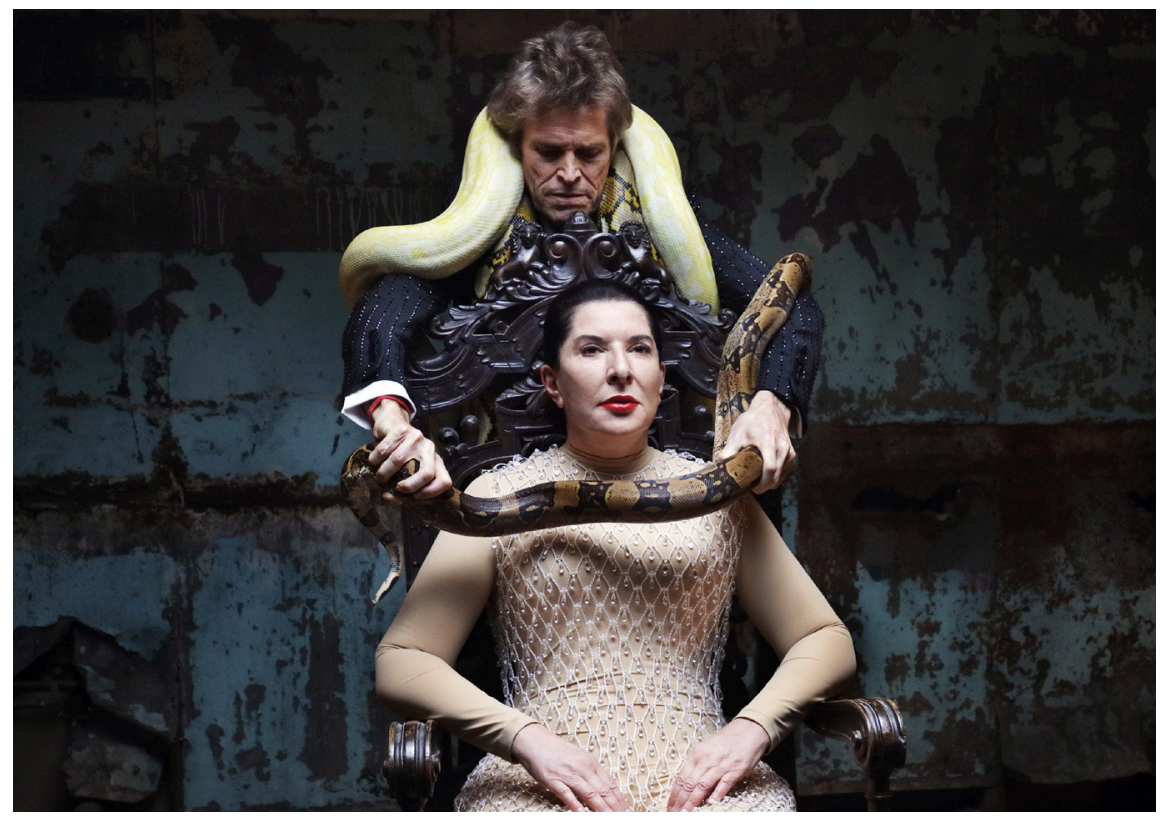

Fig. 1 Marina Abramović, 7 Deaths of Maria Callas, 2019. Photo credit: Marco Anelli, courtesy of the Marina Abramović Archives.

It might seem that the focus of the opera 7 Deaths of Maria Callas is the life, voice, and career of Maria Callas, but first and foremost this piece is autobiographical. Abramović tells us that she has been fascinated by the character and work of Callas since childhood, when as a young girl in Belgrade she discovered her voice and fell in love with her interpretations. As time went on, the relationship between Marina and Maria became more complex. Marina realized that they both have a lot in common, that they even look alike, and that their lives were marked by an unhappy love. It might be claimed that this opera is primarily about Marina Abramović, depicting her art, her status as a diva, her rise on the international art scene, her ego, her pain, her suffocation, her motionless waiting, her undressing, her youthful looks, her unhappy relationships.

Against the background of electronic Ligetian "clouds" in the interludes, Abramović as the narrator speaks of her texts inspired by operatic heroines and their deaths. Here, the disquieting, almost frightening music of Nikodijević and Kozlovački seems to "squeeze" through itself the transformed vocals. Then, towards the end of the opera in "The Eighth Death," Abramović is on stage as Callas is shown dying in her Paris apartment. In 
the final moments, Abramović is seen in a glittering golden dress, enacting slow, deliberate movements. The singing voice of Maria Callas is eventually heard, and the live, golden figure of Marina becomes like a doll. Abramović pays homage to Callas with this opera, celebrating her unique capacity to connect body and voice into a single, extraordinary whole. ${ }^{2}$

The opera 7 Deaths of Maria Callas is also a kind of didactic musical spectacle through which Abramović masterfully displays to Callas and to everyone how she herself has struggled with deaths, lives, ups, downs, and unhappy loves in different worlds, and how she has re-channeled these eternal themes in her art.

JELENA NOVAK: Why did you choose to create an opera today? What makes it different from a theater piece with music? And what is so intriguing about the genre of opera today that more and more artists, including those from the visual arts, take it as a source of inspiration or as a material to work with in their pieces?

MARKO NIKODIJEVIĆ: Opera provides an opportunity to bring different artistic media together. When successful, it can produce the kind of artistic effect and emotional impact that a purely musical work or a piece of video art, for example, cannot achieve. So, when all these different media come into a perfect union, then a type of theater magic happens, and that magic has been intriguing artists for more than four hundred years now.

JN: Marina, I know about your fascination with Maria Callas. What is it about opera that fascinates you? What exactly draws you to it?

MARINA ABRAMOvić: Maria Callas is one thing. But opera is a different matter for me. I never liked opera, I think it is so boring and so long, it is like a dinosaur in art. There was a very traditional way for people to approach opera. Any kind of change, any different point of view, would be disturbing for the public. The public really likes it done in the traditional way, as it was always done, and they want to continue with the genre in that form. It is so interesting for an artist to depart from tradition, to break the

2 These remarks on the opera 7 Deaths of Maria Callas draw on my critique written for the weekly Vreme following the world première of the piece by the Bavarian State Opera. The audience was subject to COVID pandemic restrictions, and the piece was also available for online streaming for a restricted period (this is how I watched it myself). The article is in Serbian and is available on the news magazine's website: Jelena Novak, "Operski agregat uživo," Vreme, September 10, 2020, https://www.vreme.com/cms/view.php?id=1819592. 
rules, to re-conceive the genre, and to make something new. To me, opera is one of those art forms that has never been touched, so that was reason enough for me to touch it and to put in it something really different, creating a much more complex work than opera as it has been conceived up to now. There is a video, an installation, a "situation," a performance; there are opera singers, novel musical combinations, and so many other ingredients all working to create something fresh. Normally, an opera lasts four hours, or even five hours, a very long duration for a work. This piece lasts only one hour and thirty minutes, because the act of dying takes less time than telling the story of an opera. With Marko working with me, it was really a dream to create something that stands on its own in a very original way, a way that has not been attempted before.

JN: When I look back at some of your pieces I find a fascination with the voice, and especially with the screaming voice. Some of the early pieces, like AAA-AAA (1978) that you did with Ulay, feature the screaming voice. There you screamed at each other's mouths. And there was another piece, Freeing the Voice (1975-76), performed in the Student Cultural Center in Belgrade, where you were lying down and screaming for a long time. More recently, there was the piece The Scream (2013-14) that referred to the famous canvas of Edvard Munch, in Oslo, where members of the audience were invited to scream through the frame that you constructed on the spot where Munch supposedly executed that painting. What is the relationship between the screaming and the singing?

MA: It is so very different for me, because screaming really emerges from my way of being as a performance artist, trying to find my own physical and mental limits. I wanted to scream until I couldn't scream anymore. And when you scream for such a long period of time, the voice becomes a kind of independent element, so that you start listening to things that you have never heard in your own voice: the voice of a child, the voice of a bird, the voice of anger, of fear, the voice of love. There are so many elements in the voice when you actually get to the point where you reach the limit of possibilities, where you actually scream until you lose your voice, which is what happened to me. For three months I lost my voice completely and so this was an investigation, an investigation of the body, and really had nothing to do with singing. But I worked with sounds, even before I got to performances. Sound to me is interesting, the sound itself. As for the singing, I used it in some video works, and I even sang in Bob Wilson's piece myself, 
as a technically excellent singer, but she did so with exceptional vehemence, and in a society where, of course, women were certainly not seen as equal to men. She barged in with such force and decided to impose her artistic vision. A lot of people thought that her voice, especially from the early 196os, when the registers acquired an even more extreme coloring between her chest voice and her head voice, had such an emotional impact because she had such a relentless need to communicate through music. She wasn't just a canary that was twittering around and making nice melodies... It was really life and death to her, she died constantly on stage, day after day, night after night, and she sort of traumatized herself with this endless dying, because she had died so many times. I don't know if there were many roles where she was actually alive at the end. She was either a broken woman or (usually) a dead woman. She lived through this, and it was a sort of a real-life performance. She brought herself to a state of expressing such extreme emotion with her voice and with her body that she was completely exhausted at the end. Her marvelous career ended, and she left the operatic stage at just the age of forty-three which is incredibly young.

JN: We can see that today opera more and more often becomes, so to speak, "curated" by the director. This opera project moves in this direction. In earlier times the main creator was the composer, or even before that, the librettist. But today there is a tendency in some pieces, notably with directors such as Pierre Audi or Michal Grover-Friedlander in Tel Aviv, to piece together various pieces from musical history or arias from historical operas and sort of "curate" them into the new piece. How do you see this tendency?

MA: I don't have much opinion about this. I think opera can't be made the same way it has always been made, so there can be very different approaches. The opera sets are not anymore made in a traditional way: the setting can be in a parkway, or a garage, or a hospital. The settings change, and the directors have many different ideas about how to give a new point to opera. I think it's a kind of a normal evolution.

JN: Did you have in mind any reference from the world of what we might call new opera, like Einstein on the Beach, for example?

MA: No. Einstein on the Beach, of course, I know, but I was trying not to look at anything for inspiration. I was trying to make something that is my own and original, though my original idea is more than forty years old now; I mean the idea that in every opera a woman dies in the end, so why 
not show only the deaths and nothing else? I don't think that anybody had this idea before. So, I'm showing only dying scenes through the prism of Callas. And then, there is also the eighth death. That is the death of Callas herself and we don't talk about that. We know that in the end there is a voice that comes out of the old tape recorder, and that is Callas. Marko Nikodijević did an ingenious thing: he stopped the voice in medias res, so that the voice actually continues in our heads, even if you can't even hear it. And then you understand that-yes, she can die, but her voice is immortal, her voice will never die. And that's what I would like to leave the audience with.

$\mathrm{JN}$ : I heard in some parts of the electronic music some transformation of the voice, even maybe the screaming voice...

MA: Marko went to such amazing lengths, he wanted to even record the sounds of the street where I was born in Belgrade.

MN: That was Luka [Kozlovački]'s recording of the street corner where Marina was born, which is very beautiful, because she says: "It is only Paris" and opens the windows and we hear the sounds of the Stari Grad (Old Town) from Belgrade. We had children screaming, and we were adapting the electronic part as we went along. I'm opened to revisiting and redoing some things or making them somewhat different. I don't think I have to be a living museum, so that there is just a statue and you cannot touch it and it has to be like that. I'm much more open to a sort of a live concept of music.

JN: The male voice can be heard at some point towards the end of the opera, in "The Eighth Death"?

MN: Yes, that is Willem Dafoe recycling certain sentences from operas like Carmen, Traviata, Lucia and so on, both in the original language and in English translation. In the National Theatre Munich [the Bayerische Staatsoper's main venue] it probably didn't sound the same as in the stereo mixdown for the video stream on television. It is a large opera house and has a very complete cupola so that these sounds literally go from the bottom to the top and then spin around, so that they sort of move around the whole opera house, including the audience and stage, so that you imagine you're in the midst of a storm created by this voice.

JN: 7 Deaths of Maria Callas begins with what I would call the amazing "music of bells." Listening to it, I started to ask myself if this music stands for church bells, or some other kind of bells, and I think it's extremely exciting 
but this is totally different. I don't actually see a connection between releasing the voice, where I am exploring the limits of the voice, and singing.

JN: Marko, what is your reference point for the voice, and especially the operatic voice, both the conventional operatic voice and those non-conventional voices that are sometimes used in opera today?

MN: The voice is a very limited instrument and has a very narrow range compared to most traditional instruments. But, as we communicate through the voice, we are used to registering even very small differences within it. The voice can transmit so much emotion and meaning in the smallest possible way. It is an instrument that is sitting inside our throat, and it is also somewhat fragile. We know that from opera singers who are constantly protecting their voices. At the same time, it is capable of communicating in a manner that does not exist in any other medium.

JN: What is so special about Maria Callas's voice? I was thinking about that when watching 7 Deaths. At the Munich performance we heard seven extraordinarily good singers, and it almost seemed at one point like a kind of an audition for Maria Callas, so to speak. You hear all of them, and then at the end you hear this recorded fragment of Maria Callas singing "Casta diva." At that point I realized that Callas's voice, when compared to all the other beautiful voices that we heard, exists in some kind of separate, and very special, dimension. Why do you think she has this special dimension to her voice? What is that special there?

MA: I only remember having breakfast in my grandmother's kitchen when I was fourteen years old. We had an old Bakelite radio, and I remember I heard this voice coming out of the radio. I had no idea it was Callas, and I didn't know what she was singing. I didn't understand the words-it was in Italian-and I remember that I stood up, feeling the electricity going through my body, and with this incredible sensation of emotions passing through me. I started to cry uncontrollably, and it was such an emotional effect that I have never forgotten it. After that I wanted to know whose voice it was, who was this person, and I really wanted to know everything about her. Her voice has such an enormous emotional impact, and it has some kind of electric energy passing through it, a gift that very few people in the world have.

MN: I think there are artists like Maria Callas who seem to break down conventions, the pedigreed ways of doing things. Callas invaded the scene 
to enter the opera in this kind of way. To me it was as if the church bells were ringing all the time at the beginning. And the oboe, maybe, represents the voice. If you narrated in this Introduction, how would you describe it?

MN: My starting point for this opening cloud music was actually how the clouds would appear. The first cloud sequence is one of early morning clouds. In the cloud sequences there are always these epigrammatic poetic texts before each of the film deaths, and they sort of explain, or give a poetic introduction to, what kind of a death we are moving towards. And so I looked at the clouds. It started with these morning clouds, so that is why there is so much Italian impressionism. The oboe melody is just a slowed down aria from Traviata that the singer is about to sing. "Addio, del passato" is somewhat stretched out and slowed down, but exactly the same notes are used with just a few additional flourishes.

JN: And how did you select these seven arias? Why these seven and not some others, and why precisely seven of them?

MA: Seven is my destiny number, and I really like that. Also, seven is such a biblical number, with the seven days in which God made the world... I was looking for all different types of deaths, so I actually chose tuberculosis, a leap, strangulation, burning, radiation, death from madness and knifing. I tried to present every possible way of dying, as far as I could; that was the idea. And then, also, I was looking for the best of the aria performances by Callas.

$\mathrm{JN}$ : It is intriguing to see this opera both through the prism of your art and through Callas's. At times it seemed as though you were Maria, and at other times you were Marina. You managed to entangle the two lives through this piece. Moreover, there are references to some of your other pieces in the videos.

MA: Definitely, like the snake in the video-I was doing this before in the live performance. But, talking about number seven, I also wanted to present seven types of women, all different types, and all dying for love in the world. We all die for love and we are all different types of women, and I really wanted to show this through the singers. So, we were casting people who actually represented these types. Normally, people cast singers just for their voice, but for me it was also important to see how they looked visually, and also where they came from, from a Nordic country, for example, or from Asia, or Spain-so all these elements really played a role in my deci- 
sion. I needed in this piece not just Callas. It is a Callas story, it's my story and it's seven different women's stories, because I wanted these themes to be universal, applying actually to anybody in the world dying from a broken heart, and not just one person. It's not the story of one person, but the story of all of us.

JN: And what would you say about the question of realism in opera? I think achieving realism in opera is quite an impossible task, because opera always tends to be "larger than life." Even if what we can see in the opera is realistic, the very fact that characters are singing undoes that realism immediately. How do you look at these issues of realism in opera?

MA: I was looking more into the conceptual part. I was thinking more of the fact that Callas left everything to her maid Bruna, all her possessions and all her jewelry and everything she ever had, because Bruna was the only person who was always with her. So, all of the opera singers are actually different forms of Bruna, the same maid, and they are all dressed in the same "uniform." At the end, when they come to leave the room and clean the broken glass on the floor and cover all the possessions and take away the memorabilia, you understand that, actually, Callas is not there anymore. So, I simplified the work to a point where there is indeed some kind of realism, but of a conceptually different kind. Callas's room on stage is the exact replica of the room where she really died in Paris. We examined every single photograph and reproduced the furniture, the paintings on the wall, and even the sleeping pills next to her telephone. Everything was done to enable that kind of realism. And yet within this realism, there in the bed is Callas, but also me, because of the photographs I'm looking at. I'm not looking at Callas, nor at photographs of Onassis, Zeffirelli, Pasolini, or any of her friends. I'm looking at my own photographs, at the man over whom I really did almost die of broken heart. So, it is a mixture and it is constantly going on through the piece.

[JPC]: 7 deaths of Maria Callas is truly an intermedia project. I wonder if you could tell us a bit more about its videographic component, namely about your collaboration with Nabil Elderkin and, more broadly, about how you elaborated that interaction between stage and screen. ${ }^{3}$

MA: I was looking for somebody who was doing great music videos, because this is a music video in many ways. It's not just the decoration in the back

3 This question was posed by João Pedro Cachopo (CESEM). 
that you project. I wanted the video to be the integral part of the story. Actually, I stripped the stage to nothing, to just a single singer singing in the middle. But that, in a way, is a part of the video at the same time, visually. So, working with Nabil was great for me because I found he was a great filmmaker himself. I also wanted to have just one person in the video killing me over and over again, and that's Willem Dafoe-because it's basically in the mind of Callas, with Onassis killing her constantly over and over again. So, it was a very conceptual approach. Then we lifted the stage a little bit higher, so that actually the singer became a part of the screen. So, sometimes she's entering the room, and sometimes she's a part of the killing scene, in some ways. And then there is also the bed, which is a replica of Callas's, on the stage itself, where I'm lying for an entire hour before "The Eighth Death" even gets started. So, this bed also becomes a part of the screen. In other words, the singer will go to the bed on the screen, which is on the stage, but at the same time you see the second bed of Traviata on the stage, projected on the screen, so it all gets mixed up in a single entangled web. You have to have an image that works for the public. Also, the fact that the orchestra is not in the pit-since for social distancing and coronavirus we had to raise it up-made it a part of this installation, too. It became in effect more opera installation then opera.

MA: I wanted to ask Nikodijević one question myself. How did this change affect you? Seeing the orchestra in that way and not hidden in the pit-how did that change the fabric of the music?

MN: It depends on which hall it is done in, and on how high the parquet is. For me it is mostly an acoustic thing. Being in a pit focuses the orchestral sound much more, so it sort of emerges from the orchestra pit already blended and glued together, much more so than when the orchestra is in the main hall, where there is just much more reverb. I mean, that is why Wagner used the covered orchestra in Bayreuth, to achieve the ultimate magic effect, where you don't see the orchestra at all, it is completely covered and it allows the sound to come from everywhere, so to speak. You feel that you are in the midst of this enormous ocean of sound, but that doesn't have any biting quality. There is always something very mellow produced by this covered orchestra. So, it has both a dramatic effect, and also a purely acoustic one.

JN: What Marina described worked especially well, I think, in moments when in the video-for example, I think, in the madness scene-you can see Ma- 
rina/Maria screaming, but you cannot hear the scream, you can only see the open mouth screaming and then, at the same time, you can see the singer on the stage, singing. There is a discord or ventriloquism between what we hear and what we see on stage. These moments (and there are a few of them throughout the piece) work extremely well, and they open up all kinds of questions about the continuous discord of body and voice in opera.

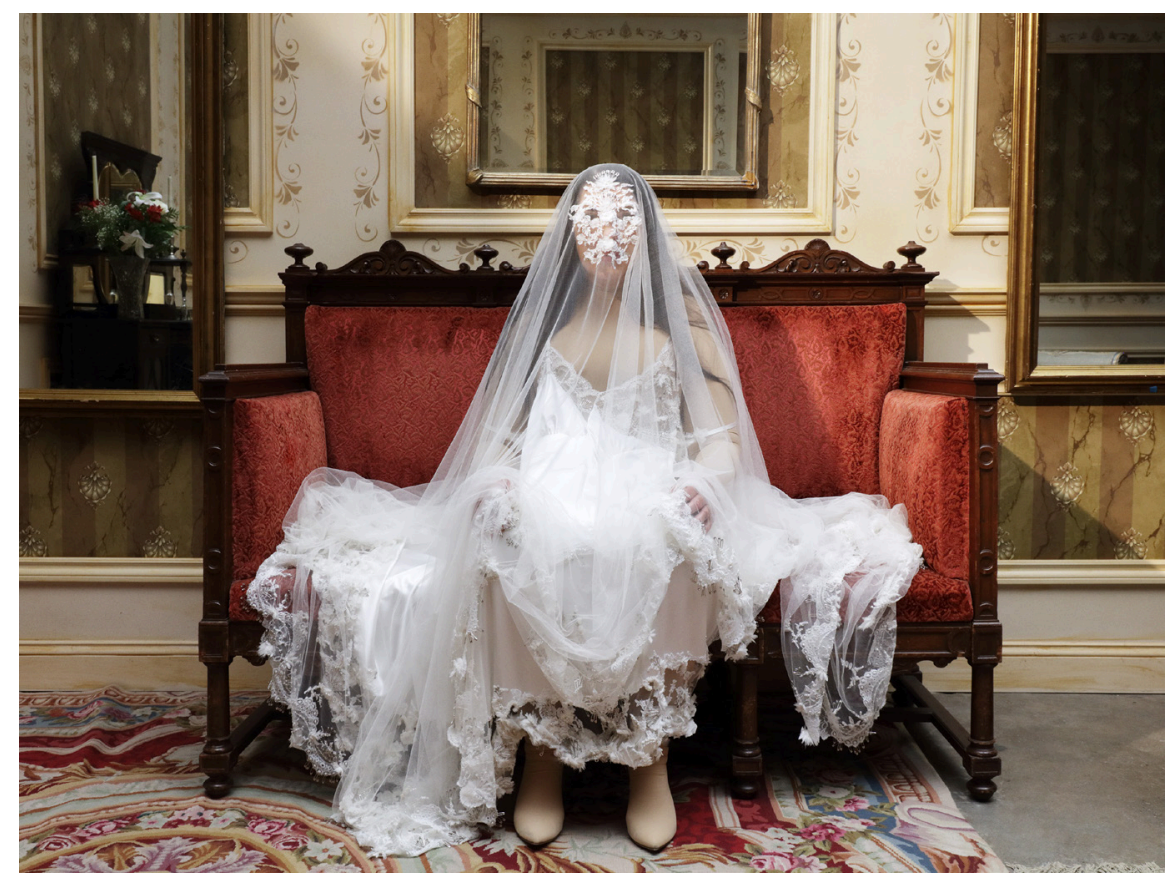

Fig. 2 Marina Abramović, 7 Deaths of Maria Callas, 2019. Photo credit: Marco Anelli, courtesy of the Marina Abramović Archives.

[FM]: Are you planning to do different versions of 7 Deaths when it will be performed in different spaces in the future? And are there also plans to put it on DVD? How can you preserve this kind of performance?4

MA: Right now, I'd really like to perform it as it is for a while. Our next performances are going to be in Paris and Athens in 2021, and at the Teatro di San Carlo in Naples in 2022. We also have plans for Berlin and New York... We would like, at least for the next two or three years, to perform it as it is.

4 This question, by Filipa Magalhães (CESEM), originated from the Zoom chat box during the interview. 
As long as I can be on the stage, I will perform this piece. I don't see any reason why we should change it and make another version. Right now, it really works for me as it is and I want to have the pleasure of doing it for a while. Moreover, every theater produces a different experience, and every audience is different. Also, different countries-how will the Italians react to this, for example, given that Callas had her biggest career in Italy; or how will the Greeks react, and what will the French say, or what will happen if we perform it in Asia? I want to experience this as long as I can.

MN: And, of course, one cannot achieve the depth of sound and visual field on a video that you have in the theater. It's just that it's a very deep three-dimensional field and you cannot recreate what you are hearing even with the best hi-fi systems. It is simply impossible to reproduce that kind of sound experience. It cannot be recorded-it's just made to be live.

MA: I have to agree with Marko completely, because, you know, the live stream and the DVD or anything else is only a form of documentation, it's not the real thing and will never be the real thing. You have to be in a theater, you have to feel, you have to smell, you have to touch, you have to be there.

JN: Marko, I understood that you re-orchestrated the piece because of the pandemic developments, since the number of people in the orchestra needed to be smaller. So, will the next performances of the piece be in this reduced version, or will you return to a bigger orchestra?

MN: That depends on the coronavirus and not on me. I mean there exists a version for reduced orchestra and a version for full orchestra, and it all depends on how many people we can have in the orchestra, and also in the audience, for which version we will use. I can manage with forty-five musicians, but I find it very hard to perform in an opera house designed for two thousand people with only three hundred people present. I mean, I know that the attention is there, but it is also a very strange situation.

MA: In Munich we gave five performances for five hundred people, which means 2500 people; it's still something, and maybe it's going to be the same in Naples, so let's see...

MN: And we had to fight for five hundred people; we were given that number on the day of the premiere...

MA: Exactly, it was a very nervous moment, but we were lucky. So, every 
time it changes, and every time we have to see what the new situation will be; we can't predict it.

[IN]: If the future is disembodied and even more distanced, physically and otherwise, what if the heartbreak ceases to exist, at least in the form we know it now? What is art going to do about that possible dystopian scenario? Why is it still important to reenact love and longing in this way as in opera?

MN: Well, I don't think the tragedy of the future will be a matter of unfriending people on Facebook, because I cannot see that platform as any kind of musical tragedy: I mean whether you get unfriended on Facebook, or your Instagram gets spammed. So, I mean, there are potentials in new technology, but obviously virtual reality and a one-dimensional "app society" is no substitute for the one thing that we feel as real.

MA: So, we like to think that loneliness, solitude, alienation, and a broken heart are thousands and thousands of years old and have always been there with us, with or without the epidemic; none of that really changes. The same goes for how art will look. The epidemic comes and goes, and right now we have to wait for a better time. I hate to compromise because of the epidemic. I hate Zoom performances with bad quality and terrible images. I just don't see this is the right way to go. I really think we don't need to compromise. We just have to wait. That's it.

5 This question was posed by Iva Nenić (Faculty of Music, Belgrade). 
Since the beginning of her career in Belgrade during the early 1970s, Marina Abramović has pioneered performance art, creating some of the form's most important early works. Exploring her physical and mental limits, she has withstood pain, exhaustion, and danger in her quest for emotional and spiritual transformation.

Abramović was awarded the Golden Lion for Best Artist at the 1997 Venice Biennale. In 2010, Abramović had her first major US retrospective and simultaneously performed for over 700 hours in The Artist is Present at the Museum of Modern Art in New York. Abramović founded Marina Abramović Institute (MAI), a platform for immaterial and long durational work to create new possibilities for collaboration among thinkers of all fields.

Her most recent publication is Walk Through Walls: A Memoir, published by Crown Archetype on October 25, 2016. Her retrospective The Cleaner opened at Moderna Museet, Stockholm in February 2017 and has toured to seven additional European venues, ending at the Museum of Contemporary Art, Belgrade, Serbia in 2019. In September 2020 the Bayerische Staatsoper presented the world premiere of 7 Deaths of Maria Callas, which will continue to tour to other venues. In 2023 she will present the solo exhibition After Life at the Royal Academy, and become the first female artist in the institution's 250 year history to occupy the entire gallery space with her work.

Jelena Novak is a researcher at CESEM (Center for Study of the Sociology and Aesthetics of Music), FCSH, Universidade NOVA de Lisboa. Her fields of interests are modern and contemporary music, recent opera and musical theatre, music and new media, capitalist realism, voice studies in the age of posthuman and feminine identities in music. Exploring those fields, she works as a researcher, lecturer, writer, dramaturge, music critic, editor, and curator focused on bringing together critical theory and contemporary art. She has been a founding committee member of the Society for Minimalist Music and a founding member of the editorial collective TkH [Walking Theory]. In 2013 she won the Thurnau Award for Music Theatre Studies from the University of Bayreuth, Germany. Her most recent books are Postopera: Reinventing the Voice-Body (Routledge, 2015), Operofilia (Orion Art, 2018) and Einstein on the Beach: Opera beyond Drama (co-edited with John Richardson, Routledge, 2019). She is currently co-editing (with João Pedro Cachopo) a special issue for Opera Quarterly dedicated to operas based on films and preparing the co-edited volume (with Kris Dittel) Singing beyond Human.

Marko Nikodijević was born in 1980 in Subotica, Serbia and studied composition in Belgrade with Zoran Erić and Srdjan Hofman between 1995 and 2003. In addition, he attended courses and lectures in nonlinear mathematics and physics. Following his education in the Serbian capital, he undertook advanced training in composition with Marco Stroppa at the Academy of Music and the Performing Arts in Stuttgart in 2003. Nikodijević settled in Stuttgart, from where he received stipends and attended master courses and composition seminars in Apeldoorn, Visby, Weimar, Amsterdam, Salzwedel and Baden-Baden. His compositional production has won prizes and awards at the International Young Composers Meeting in Apeldoorn, the Gaudeamus Music Week in Amsterdam, the 3rd Brandenburg Biennale and the UNESCO Rostrum of Composers.

He resided in Paris from 2012 to 2013 as a scholarship holder at the Cité internationale des Arts. In 2013 Marko Nikodijević received one of the three composition furtherance prizes of the Ernst von Siemens Music Foundation and in 2014 was awarded the Deutscher Musikautorenpreis (German Composers' Prize) in the category Promotion of New Talent. 